\title{
Innovation of English teaching methods
}

\author{
Zhao Hui Min ${ }^{1, a}$ \\ ${ }^{1}$ Bohai university, Jinzhou, 121013 China \\ ahmzhao2008@163.com
}

Keywords: English teaching; innovative thinking; method innovation; method discussion; reverse thinking.

\begin{abstract}
Innovation is the soul of a nation's progress and the inexhaustible motive force for the prosperity of the country. Cultivating students' innovative ability is the basic direction of educational work. To implement innovative education, we must first change the concept of education, and permeate it into all the teaching activities. The task-based teaching should be student-centered, inspire and mobilize the students to actively participate in teaching activities, and guide the students themselves to study, analyze and solve problems, and cultivate students' innovative spirit, and improve the students' cognitive interest, curiosity and creativity. This requires educators to choose appropriate methods, timely create an atmosphere of innovation, and cultivate the ability of creative thinking of students.
\end{abstract}

\section{Introduction}

Innovation ability is the core quality of individual quality, innovation education is the highest form of quality education. Innovation education is the extension and improvement of quality education and it is a new realm of quality education. Therefore, the focus of the current quality education should be put on innovative education, and actively explore the characteristics, rules, content, requirements, methods of innovative education to promote the improvement of the quality of students and the whole of the Chinese nation. The innovation includes both "and" out of thin air, including innovation". The innovation ability of students has innate ingredients, but is mainly acquired, but also through knowledge, skills, methods, innovation strategy teaching, and cultivating and training in solving problems. In the new curriculum teacher training to promote participatory approach, is the embodiment of the people-oriented, to the teacher professional development of the new training concept. In the practice of training, participate in the whole process of training. First of all, students should participate in the design of training. At the initial stage of our training, training content and methods of questionnaire survey, and students proposed to adjust or modify according to the training plan, to make the plan and their training needs consistent. Second, students participate in the training activities. Not only the group cooperation[1], class communication itself is full of participation in the activities of the other is generally considered to be less involved in learning activities, but also reflects the spirit of participation. For example, in the lecture of this session, participants read the lecture on the outline of thinking, for their problems with listening, listening to the thinking process in the side, take the initiative to build an own understanding, the meaning of their own content structure. Third, to participate in the evaluation of training. Part of the training, contents and methods, through let students fill in the feedback form, interview evaluation activities in the form of training activities, and encourage students through reflective experience, to evaluate its training effect.

\section{Concept first, the creation of atmosphere}

\section{Change education concept.}

Change the concept of education is not only a vague concept, but should have specific connotation. From the perspective of the overall implementation of quality education, based on the status of education today, especially the new curriculum reform we need to update the concept of education, challenge the traditional idea of evaluation in the teaching activities, pay more attention to the 
humanities, stimulate students' potential, focusing on capacity and process as well as the emotional attitude of students. Teachers should have a clear and profound innovative teaching ideas and innovative spirit. The basic characteristics of the traditional concept of education is to impart knowledge as the center, too much emphasis on the role of teachers, and the new education in the teaching process to reflect the "students as the main body, the teacher as the leadership, training as the main line, thinking is the core of the teaching thought, respect personality and creative spirit of students. The teaching focus and standpoint to guide the students to actively" learn "to guide students to learn and learn well at learning. Only when the teachers continue to learn, to contact new things, continue to enrich themselves, to continue to forge ahead, with its own positive factors of innovation consciousness, thinking and ability to promote the formation of students' awareness of infection, and gradually cultivate students' innovation consciousness. In English teaching to cultivate students' sense of innovation, but also pay attention to the protection of students' unique personality, and give students the freedom to give full play to the personality. The implementation of innovative education, not only should be good at understanding, but also should be good at "listen" to the students talk[2], for each of the students are interested in. The teacher for students, love and care about each student, especially students, respect and understand students, to eliminate prejudice, unconditional love and care for students, with positive expectations of students, students' trust. This is the teacher's duty. Teachers should be more aware that if you don't love and hate your students, your education has not yet begun. Although you can not say that you give the students a piece of ice, students will give you the whole cold, but if you give students a bunch of flowers, the students will give you all the spring. The process of teaching is not a process of knowledge, but a kind of interpersonal process. Students learning to launch, mainly depends on the attitude of the two sides of the relationship between teachers and students. This attitude is true, recognition and understanding.

\section{Giving full play to the main role of students is the driving force for the reform of the new curriculum.}

The implementation of innovative education, teachers should change the traditional monopoly platform, enhance the interest of teaching, creating a lively atmosphere in the classroom, create a democratic and open teaching situation, teaching process will process the sharing of experiences for teachers. Teachers should also help students break the traditional sense of authority. Scientific knowledge, worship of the great man, absolutely believes that teachers, these are the students of the traditional authority of consciousness. The consequence is that the students have lost the space of free thinking and Reflection on the past. This determines the conversion of the role of teachers, should not only attach great importance to the cultivation of knowledge and ability, should pay more attention to cultivate and stimulate the students' interest in learning, to develop good study habits; the teaching content, from the simple language teaching to both languages, and cultural and scientific knowledge, edify sentiment, cultivate noble sound personality; in teaching methods, to study the new teaching methods, to study teaching method and learning method guidance, realize the purpose of development of students' innovative ability. Teachers should learn to listen, learn to check the hole. In order to promote the growth of student's knowledge, in the beginning of teaching, teachers need to retain their own opinion, and to listen to the idea of the students. To truly understand the inner world of the students, you need to have the mentality of communication, there is a profound insight. Curriculum reform requires teachers must change their roles from imparting knowledge to the role of education facilitators, organizers etc. As the organizer, facilitator of teacher education, the task should be student-centered; to inspire and mobilize the students to actively participate in teaching activities, and guide the students themselves to study, analyze and solve problems, to improve the students' cognitive interest and desire for knowledge. At the same time, teachers give appropriate advice, more research, discussion and exchange. Even if there is a chance of cooperation, students can have a certain freedom to choose the content of learning, but also the key to achieve innovative education in the classroom teaching. Teachers should create a pleasant and harmonious, democratic, loose social environment for students, teachers should strive to good emotion to students to lead the students' positive emotional reaction, the creation of emotion atmosphere between teachers and 
students. Enable students to explore new knowledge actively, highest interest, knowledge and skills to the pursuit of human wealth in a relaxed and harmonious atmosphere for learning, so that students dare to innovate, create and burst out the spark of thought. The teacher should be for students to create opportunities, enhance the confidence of the students in the process of self-expression, and improve the ability of innovation [3].

\section{Give full play to the subjective initiative.}

In the course of teaching, teachers should give full play to the leading role of teachers and students' main role, and cultivate students' sense of participation and cooperation. First of all, to provide students with the opportunity to participate in teaching, and constantly inspire and guide their learning interest, to provide them with the time and space to think and create. If you teach the appearance of the characteristics of teaching, you can first describe any student in the class: has long hair. Her face is she round. Her eyes are big. She is tall...... Who is she Guess? after the students guess, you can let the students try to describe other students. This kind of teaching method can arouse students' psychological eager to enable students to personally participate in the process, to experience the joy of success. Secondly, to strengthen the classroom discussion, strengthen students' sense of competition and innovation, raise the ability of students to ask questions and solve problems. Finally, the introduction of English games into the classroom, in the game to cultivate students' imagination and participation awareness. In the classroom to carry out more work Team, work Pair, work Group and other teaching activities, teachers and students in the activities of mutual discussion, evaluation, inspiration, motivation, thus opening up the student's thinking space, improve students' innovative thinking ability. The traditional education in the "spoon feeding" teaching method that can cultivate students' innovative thinking and ability, and only by discovering, heuristic, discussion and other advanced teaching methods, in order to mobilize the initiative and awareness of students, inspire positive thinking, take inspiration, guidance, active participation, guiding students' independent thinking, looking for the possibility of the answer; students dare to criticize and innovate spirit; cultivating students to discover problems, analyze and solve the problems of courage and ability. From the actual situation, according to the different teaching contents, different teaching objectives, different equipment, different levels of students, teaching methods of one or several optimal, comprehensive use of this requires that we should have the spirit of reform and innovation, but also focus on the actual effect. Only the English education in primary school, to cultivate students' autonomous learning activities through participation, gain experience, and gradually formed a kind of daily life and learning, to explore a skeptical psychological tendency, strive for knowledge. It should also cultivate the ability to discover problems, to put forward problems and to solve problems, to collect data, to analyze the data and the ability to draw conclusions, as well as the ability to express ideas and exchange results [4].

\section{Strive to create a real life situation, flexible use of language}

\section{Creating a real life scenario.}

The creation of real life situations, provide a lot of opportunities for students, including dialogue, role play, games, stories, group activities and practice, let them play, sing, play games, get a surprise, so as to make the classroom full of fun. The classroom posted a series of oral English, English charts and English newspapers, books, letters, postcards, pictures show the vocabulary, so that students in an English environment. Often in the course of internal and external use of positive and incentive evaluation methods to encourage students to create a good learning environment, the students in a timely manner to discover the flash point, and feedback to the students at any time. If you speak accurately, answer questions loud...... In particular, teachers should grasp and appropriate use of a variety of evaluation methods, reflect the development process of students, pay attention to individual differences, to play the initiative of students and to promote students' self reflection. Especially in English teaching, no one can learn a language without making mistakes. If the student is afraid of failure and they don't try to use new words and sentences, naturally can not make progress. The 
students in the language structure try to use new, often requires great support and help, instead of constantly correcting his speech and words. Therefore, teachers should try to praise and encourage the students, and to provide a lot of demonstration and tips to help the students to use the new words and phrases. Only in this harmonious and relaxed learning environment to cultivate students' thinking mode and thinking quality, so that students learn autonomous learning, it is possible to explore and create.

To attach importance to the study of law and to cultivate the ability of self-study is the key. The ancients said: "teach people to fish, as delegated to the fish." Teachers not only to teach students knowledge, more important is to teach students to acquire knowledge of the methods and skills, in order to achieve the purpose of lifelong education, to provide high quality personnel for the modernization. Therefore, guiding students to learn the correct way to cultivate good learning habits and self-learning ability, to stimulate students' enthusiasm for learning is the key to English teaching. Can design a set of questions, the article further makes students along successive teachers, teachers guide way step by step, and finally achieve or make students according to see light suddenly, the guidance of teachers to discover, explore, and draw the conclusion. At the same time, we can run the English corner, English speech contest, English Festival and other forms, let the students brain, moving mouth, eye movement, to enable students to get hands-on, motivation, inspiration, imagination, inspiration, training and cultivation of creative ability, guide students to widely Lenovo, multi angle of view for the training of divergent thinking for the students, and lay the foundation for the development of creative thinking.

\section{Innovative English teaching, the use of the method to be appropriate.}

The implementation of innovative English teaching, the choice of the method is the key. The success of creative teaching of English is very important to choose the right method. On the teaching practice of the author to talk about several innovative teaching methods:

1 guide - inquiry

To cultivate students' creative thinking, to train the ability of language expression and to summarize the ability of summarizing. This process mainly adopts the principle of "taking teacher as the leading and taking students as the main body", that is, the students to explore independently under the guidance of teachers, teachers will give the necessary guidance and guidance. It was introduced into the teaching method, that is, before the formal teaching of new courses, starting from the title, supplemented by background knowledge, for the teaching content, to carry out the question and answer activity. In the design, to provide students with the space for speculation and creation, and make it in the upcoming content to be confirmed and denied. Such classroom design is the goal of thinking and creativity. Students in this class, always in a concentrated, positive and nervous thinking, and actively speak, so that students can exercise and cultivate creative thinking.

2 demonstrations - imitation

This is a teaching mode to cultivate students' skills and skills. It emphasizes the teacher's demonstration and the students have the purpose of imitation. Through imitation, play and improve the students' attention, observation, imagination and thinking ability. To imitate writing as an example. In view of the general situation of students' writing ability is poor, the comprehensive course of college experience English (the first one) design a writing model and a practical writing model, which can provide reference for students to write compositions. The students to imitate conveniently, make students follow; while reducing the difficulty of writing, to enhance students' confidence in writing; expand thinking in model based on innovation. Students in the process of imitation, thinking ability and creativity at the same time get exercise.

3 guidance - self - learning style

This method is applicable to the students who already have a certain knowledge and learning base, but it is lack of the teaching environment of independent study ability. The teacher must first rule self-study requirements, through self-study to achieve the purpose of prompting students to "learn" to 
"learn", learning process of students is also a question, and the guidance of teachers is a process of eliminating the. This method will lay a good foundation for the creative problem solving.

4 question - discussion type

This method requires careful design of the problem, the students as the main body of discussion, from the proposed issues to be refined, summarized and summed up. Students thinking, participate in the discussion of excitation in the process of teaching, to cultivate students' divergent thinking ability, improve the ability of oral expression ability and students' logical thinking, so as to achieve the purpose of "learning".

\section{Constructing the social interaction of the professional knowledge structure}

\section{Strengthen cooperative learning.}

The new curriculum advocates cooperative learning, which is the idea that "teachers are the best professional development resources". Practical training is the same or similar, will serve as the teaching task of participating in the training of teachers in the same group, each group set a consultation for the hot topic of, then according to the theme, group together to complete the problem and countermeasure analysis table, including found the problem, find out the cause and countermeasure of project consultation. Each team member has to undertake or focus on a task, and the task of the first independent thinking. In the group discussion, the members first introduced their own thinking about the problem, and then in the exchange of other members of the group, the question, revise and improve the process, the construction of collective sharing of common sense. And then, when the group exchanges, the group on behalf of the group to discuss the results of this group, and other group members in a larger range of communication. In the end, all the students and the instructor to evaluate the situation of the group. Through cooperative learning, learners can grow together in the process of interaction and cooperation. The discovery of the problem, to find out the reasons, the process of cooperation negotiation methods, each member of the teaching experience can become members of other mutual learning resources, each learner's wisdom can be transformed into the team sharing wisdom. The characteristics of different life experiences and work so that all members may have a different view on the same problem, it is in the process of collision, the different views of consultation and reflection, the individual can begin to integrate the experience of resources, and complete the reconstruction of self experience at a higher level. Therefore, cooperative learning can give full play to the individual's wisdom and ability and group interaction learning social effects to the greatest extent, which has different learning ability and knowledge structure of the learners to achieve complementary advantages, make the whole is greater than the sum of the parts of the best team effect. This process is the process of mining, expanding and upgrading of their own experience, which can effectively improve the teaching efficiency of teachers [5].

\section{Transformation from concept to behavior change.}

Experiential learning theory holds that knowledge comes from human practice, and in turn is applied to the practice of human beings. Knowledge is produced; it is to solve practical problems. Learning is to stimulate the learner's thinking, to give learners some things to do and not just to give them something to learn ". Therefore, the study should pay attention to not only the content of learning, but also should pay attention to the process of learning, namely, how to do". If Dewey's "doing" in the above theory is mainly focused on empirical operation, the knowledge construction community theory proposed by Scardamalia et al. This "do" not to produce a specific object for the purpose, but to generate a new concept of goods - thinking, therefore, "do" is essentially a kind of ideological processing activities (with ideas working).

The teacher training in the new curriculum advocates the teaching activities, because in the process of teachers' professional development, in addition to the education and teaching concept, but also need the teacher under the guidance of education theory, continue to accumulate and enrich their teaching experience, constantly enhance their practical wisdom, realizing the transformation from knowledge to knowledge of the use of reserves. Practical wisdom is silent, it is implicit in the process of practice, 
only in the specific practice to find and improve. This shows that the internalization of theoretical knowledge can be realized in practice. Therefore, we in the training in order to carry out the lesson as the carrier of the emphasis on professional guidance and Act-Up combination -- case study. First of all, the students and the guidance teacher's work together to discuss a typical teaching case, in order to reveal the guiding teaching concept and the teaching phenomenon. On this basis, the student individual or by the individual to form a pair combined with their actual teaching situation, according to the new teaching material in a content design lesson plans. The first lesson plans in group communication, and then display in the class (i.e., class) while carrying out teaching evaluation and discussion class activities in the class, the students to further revise and improve the teaching plan, the teaching design as the final portfolio of formative evaluation results in students of students. In this process, teachers are guided to participate in the whole process and give the students the guidance of theory or method.

\section{Summary}

To sum up, the knowledge age needs to have a rich imagination and great creative talents. This requires teachers in the teaching of English, according to the content of the course offered, design to stimulate the thinking of the scene and the environment, put forward the problem of thinking, so that the whole classroom is full of positive and innovative atmosphere. Encouraging students to independent thinking, bold questioning, guide students from multi angles of view, thinking of ways to solve the problem, develop the habit of innovation and innovative, to inspire students' enterprising spirit, develop the creativity of students, training students to dare to explore, innovation, good at thinking, cross century talents with comprehensive good quality. The cultivation of students' innovative spirit is not a short duration of time can be achieved remarkable results, it is a system process, in the process of teaching must be gradual, long-term adherence, teachers need to constantly sum up experience in teaching, we learn from each other. Only in this way can achieve the desired results. Twenty-first Centuries is coming to us. In the face of knowledge economy, the challenges of the new century, our educators should use education innovation to realize quality-oriented education, complete the qualified talents needed in history gave us the raise modernization of history.

\section{Acknowledgements}

This work is supported by Social Science Foundation of Liaoning Province (No. L15DWW005) and Bohai University Teaching Reform Project (No.BDJG15QNB002).

\section{References}

[1] Wu Wen, Zheng Hongping. On Chomsky's theory of language evolution -- a discussion with Liu Xiaotao, He Zhaoan (Journal of Shanghai International Studies University), 2012 (01).

[2] Tao tomorrow. Study on the environmental factors and Countermeasures of the development of primary school English textbooks [J]. curriculum, teaching materials and teaching methods. 2011 (10).

[3] Wu Wen, Gan Yong. Study on two language acquisition from the perspective of social culture [J]. Journal of Beijing International Studies University 25 (06): 2011.

[4] Wu Wen. Social culture theory and ecological language teaching view [J]. Journal of Tianjin foreign language university. 2011 (03).

[5] Leeson, Zhao Xin. Cultural perspective on the reform of teaching methods [J]. curriculum, teaching materials and teaching methods. (04) 2011. 